\title{
CULTURAS LÚDICAS NA INFÂNCIA: AS POTENCIALIDADES DE UMA BRINQUEDOTECA UNIVERSITÁRIA
}

\author{
Evandro Salvador Alves de Oliveira, Cristiane Oliveira Souza, \\ Danielle Oliveira Freitas, Wellington Sousa Lima, Ramão Marques \\ dos SANTOS Filho
}

\begin{abstract}
Resumo: $\mathrm{O}$ objetivo do artigo é discutir potencialidades existentes em um dos vários espaços que meninos e meninas brincam e produzem culturas (lúdicas), como a Brinquedoteca Universitária. É fato que as crianças, suas brincadeiras, ludicidade e vicissitudes, têm sido alvo de muitas investigações que as colocam, muitas vezes, no centro das discussões acadêmicas. A interação entre crianças, docentes, graduandos e pesquisadores provocam ações que exercem impactos na sociedade, frutos de constantes relações e intercâmbios. Por meio de um projeto de extensão, a Brinquedoteca aproxima comunidade e Universidade por propiciar a realização de pesquisas a partir de metodologias que se apropriam de intervenções, oficinas e observações participantes. Como grupo de extensão e de pesquisa preocupado com o direito infantil de "brincar", vislumbra-se explorar elementos advindos da cultura midiática, por meio de fenômenos que acontecem no interior da Brinquedoteca com crianças e professores da rede pública.
\end{abstract}

Palavras-chave: Crianças. Brinquedoteca. Extensão universitária. Potencialidades. Brincar.

\section{PLAYFUL CULTURES IN CHILDHOOD: THE POTENTIALS OF A UNI- VERSITY TOY LIBRARY}

\begin{abstract}
The aim of the article is to discuss existing potentials in one of the various spaces that boys and girls play and produce cultures (playful), such as the Toy library. It is a fact that children, their games, playfulness and vicissitudes, have been the subject of many investigations that often put them at the centre of the academic discussions. The interaction between children, lecturer, undergraduates and researchers provoke
\end{abstract}


actions that cause impacts on society, which are fruits of a frequent relationship and exchanges. Using an extension project, the Toy library approaches community and university by providing research from methodologies that appropriate interventions, workshops and participating observations. As a group of extension and research concerned with the children's right to "play", a glimpse of exploring elements from the media culture, by means of phenomena that happens inside of the Toy library with individuals and teachers of the public education network.

Keywords: Children. Toy library. University extension. Potentiality. Play.

\section{CULTURAS LÚDICAS EN LA INFANCIA: LAS POTENCIALIDADES DE UNA JUGUETECA UNIVERSITARIA}

Resumen: El objetivo del artículo es discutir potencialidades existentes en uno de los varios espacios que los niños y las niñas juegan y producen culturas (lúdicas), como la Juguetoteca Universitaria. Es un hecho que los niños, sus bromas, ludicidad y vicisitudes, han sido objeto de muchas investigaciones que las colocan a menudo en el centro de las discusiones académicas. La interacción entre niños, docentes, graduandos e investigadores provocan acciones que ejercen impactos en la sociedad, frutos de constantes relaciones e intercambios. Por medio de un proyecto de extensión, la Brinquedoteca aproxima comunidad y Universidad por propiciar la realización de investigaciones a partir de metodologías que se apropian de intervenciones, talleres y observaciones participantes. Como grupo de extensión y de investigación preocupado por el derecho infantil de "jugar", se vislumbra explorar elementos provenientes de la cultura mediática, por medio de fenómenos que ocurren en el interior de la Juguetes con niños y profesores de la red pública.

Palabras clave: Niños. Sala de juegos. Extensión Universitaria. Potencial. Play.

\section{INTRODUÇÃO}

A criança contemporânea, seus modos de ser, brincar, bem como suas vicissitudes, cada vez mais tem sido alvo de muitas discussões e investigações no campo acadêmico. Neste trabalho, partimos do seguinte lugar: dos estudos situados na área da sociologia da infância, que valoriza os discursos infantis ao dar vez e voz às crianças, colocando-as em lugares privilegiados na ciência.

Discutir a infância exige despir de concepções cristalizadas e engessadas em décadas passadas, em que investigadores a analisavam a partir da visão adulta, refletindo sobre suas práticas e condutas sem considerar os conteúdos 
e conhecimentos que as crianças carregam. Na esteira desse pensamento, no âmbito universitário temos explorado bastante essa questão, por meio de projetos de extensão e pesquisa, ao dialogar com estudantes, professores e professoras da rede pública da Educação Infantil, sobretudo com as próprias crianças.

Cabe realçar que projetos desenvolvidos no âmbito da pesquisa e extensão, em contextos universitários, visam, por excelência, ampliar os horizontes dos estudantes por meio de ações que envolvam a comunidade a partir dos conhecimentos teóricos adquiridos (previamente) na sala de aula.

Articular o tripé que sustenta a educação superior - ensino, pesquisa e extensão - é bastante desafiador e oportuno à problematizações e reflexões. Produzir ciência de modo concomitante com a formação profissional torna-se possível ao passo que durante o período de formação, estudantes e professores potencializam e provocam a construção do conhecimento em vias de mãos dupla. Ao interagir com a sociedade, por meio de eventos ou projetos de extensão, por exemplo, acadêmicos e docentes são capazes de observar, intervir e, consequentemente, educar.

Nesse sentido, trazemos aqui, para o debate, potencialidades de um projeto de extensão desenvolvido no Ensino Superior, denominado "Brinquedoteca" Universitária”. Este tem sido conduzido por um grupo de estudo, pesquisa e extensão composto por professores e estudantes do curso de Educação Física de um Centro Universitário do interior de Goiás.

Como grupo de investigadores interessados e preocupados em assegurar um direito da criança, de "brincar", pretendemos apresentar e explorar oficinas e episódios suscitados no interior da Brinquedoteca. Trata-se de intervenções que escapam de visões fragmentadas sobre a infância, pois temos nos debruçado em fenômenos que acontecem no cotidiano a partir de interações e relações que ocorrem com crianças e professores da rede pública de ensino, participantes do projeto, na Brinquedoteca Universitária.

Com base nos estudos e investigações do campo da Sociologia da Infância, em que nos são importantes as análises de Sarmento (2005), Prout (2010), Qvortrup (2010) e Corsaro (2011), a título de ilustração, compreendemos a

1 A Brinquedoteca Universitária, construída a partir de um financiamento do programa Pró-Docência, da CAPES, é um espaço amplo e confortável, preenchido com brinquedos bem diversificados. Recebe semanalmente crianças de duas escolas municipais localizadas nas proximidades da faculdade. 
infância como uma importante categoria estrutural da sociedade, por reconhecermos as crianças enquanto sujeitos produtores de cultura e atores sociais. Nessa ótica as crianças são membros ativos dos contextos sociais, possuem direito de opinar, questionar, posicionar e criticar por, também, pertencerem ao mesmo mundo em que nós, adultos, estamos inseridos.

Assim, para avançar com as análises sobre as potencialidades de uma Brinquedoteca Universitária, importa esclarecer que perseguimos dois objetivos distintos, considerando os projetos de extensão e pesquisa ${ }^{2}$ que, respectivamente, temos desenvolvido. O primeiro deles busca proporcionar às crianças, de 3 a 5 anos, da rede pública municipal de Educação Infantil, e a seus professores, um espaço para produção de culturas (lúdicas) infantis, bem como oportunizar a realização de práticas educativas mediadas pelo brincar, por meio da atuação de profissionais que atuam no campo da Educação Física. O segundo objetivo, atrelado à pesquisa, consiste em conhecer as representações e as práticas motoras das crianças que acontecem no Laboratório de Ludicidade (Brinquedoteca) a partir das interações estabelecidas com as personagens da mídia.

Desse modo, aliamos à sociedade ao unir com professores da Educação Infantil, e as próprias crianças, para compreender mais sobre determinados assuntos desse universo, assim como peculiaridades infantis e suas vicissitudes. Sublinhamos que temos trabalhado com metodologias de intervenção-ação, inspiradas também na etnografia, que nos permitem aproximar da criança, observando suas ações brincantes de modo a participar, modificar, afetar e intervir em suas práticas.

Acreditar que a criança é um sujeito como uma tabula rasa é um preconceito que perseguiu séculos, mas que já foi superado. Portanto, temos a criança e o brincar como objeto de estudo e alicerçamos nos estudos da sociologia da infância para mostrar e realçar o contrário dessa visão errônea sobre as crianças. Realizamos, na Brinquedoteca, observação participante de modo a permitir que elas manifestem livremente opiniões, condutas, expressões e maneiras de agir, por meio de brincadeiras e atividades lúdicas.

A interação entre crianças, docentes, graduandos e pesquisadores provocam ações passíveis de investigação que exercem impactos na sociedade,

2 A título de esclarecimento, o projeto de pesquisa, articulado à extensão, possui parecer de aprovação emitido pela CONEP, para efeitos de respeitar as questões éticas que envolvem seres humanos na pesquisa em Ciências Humanas e Sociais. 
frutos de constantes relações e intercâmbios. Desse modo, por meio de um projeto de extensão, a Brinquedoteca aproxima comunidade e Universidade por propiciar a realização de pesquisas a partir de metodologias que se apropriam de intervenções, oficinas e observações participantes, como apresentaremos mais adiante.

\section{A CRIANÇA CONTEMPORÂNEA E SUAS VICISSITUdES}

As crianças imersas na cultura contemporânea não são as mesmas de tempos atrás, como aquelas do século passado que brincavam com objetos bem diferentes daqueles que existem na atualidade. As crianças de hoje, desde muito pequenas, se apropriam de equipamentos tecnológicos e digitais que caem em suas mãos desde os primeiros passos que registram no mundo.

Por meio de suas ideias, imaginações, jogos, brincadeiras e ações, crianças, em suas vicissitudes, intervém no mundo de maneira cada vez mais crítica reforçando o protagonismo infantil no contexto social. Em outras palavras, o lugar da criança na escola, na política, na rua, nos espaços sociais, entre outros, tem sido alvo de muitas pesquisas no universo acadêmico.

Vicissitudes é uma expressão elegida por nós, que significa sequências de mudanças ou transformações, acasos que acontecem cotidianamente, inconstância, instabilidade, variabilidade, etc., para pensar no que é ser criança a partir de tal termo. As crianças são sujeitos que nos instigam e provocam a refletir por meio de suas constantes transformações e modos diferentes de ser, agir e estar. Quando brincam, na Brinquedoteca, assumem papeis e os modificam em espaços muito curto de tempo. Formulam frases ao responder perguntas de adultos e as interrompe rapidamente também. Se a criança julga ser pertinente responder, esclarecer ou descrever algum episódio, o faz, senão, ignora.

Percebemos, então, constantes mudanças nas ações e brincadeiras das crianças, seja quando estão na escola ou em outros espaços, como a Brinquedoteca Universitária. O contato com jogos e brinquedos diferentes, como aqueles que possuem na Brinquedoteca, provocam algumas dúvidas durante a escolha do objeto a ser utilizado para brincar.

Atualmente, no mercado do mundo capitalista, encontramos diferentes tipos de brinquedos e jogos. Nesse âmbito, o que aprendemos sobre a Escola de Frankfurt, a respeito da "Indústria Cultural", nos faz sentido à medida que compreendemos a mídia como aspecto que provoca alienação dos sujeitos, o 
que faz, muitas vezes, inibir a capacidade de reflexão crítica sobre uma determinada realidade. A indústria cultural contribui, portanto, para o crescente movimento e expansão de objetos na sociedade regida pelo capital, estes que tem sido produzidos de maneira cada vez mais frágeis e programados para o descarte rápido, direcionando para uma vida de consumo.

A esse respeito, Poletto (2005) colabora ao comentar que houve, a partir da Segunda Guerra Mundial, uma maior incorporação de brinquedos de plástico no mercado infantil. Nesse mesmo período houve, também, aumento da violência nas ruas, fazendo com que as crianças ficassem presas em casa, tendo a televisão e os brinquedos como companhia.

Nesse sentido, a mídia torna-se uma protagonista no dia a dia da criança, preenchendo a lacuna causada pela ausência dos pais ou responsáveis. A cultura midiática construída com a televisão contribui para substituir brincadeiras de mobilidade corporal, como as brincadeiras de rua, por jogos eletrônicos e vivências/experiências com tecnologias digitais. Prestes e Tunes (2012), ao discutirem a brincadeira infantil na perspectiva histórico-cultural, salientam esse fenômeno.

É brincando que as crianças combinam o que viram, ouviram, sentiram e criam as situações imaginárias, afirmam Prestes e Tunes (2012, p. 24). Conforme os autores argumentam, professores da Educação Infantil precisam abandonar aspectos tradicionais e deixar de ver a brincadeira como um espaço exclusivamente pedagógico, estes que visam moralizar e direcionar as ações das crianças. Como pontuam Prestes e Tunes (2012), a brincadeira das crianças é um espaço de liberdade e de criação, que precisa ser respeitado.

Reconhecemos que são vários os fatores que influenciam a construção e execução de movimentos (corporais), brincadeiras e jogos na infância. Poletto (2005) defende o pensamento de que as crianças se desenvolvem a partir da socialização e interação com pessoas, creches, escolas, comunidades, famílias e instituições. A Brinquedoteca, nesse sentido, se caracteriza como um espaço capaz de promover a socialização das crianças com outras crianças e com adultos educadores.

Quanto mais experiências lúdicas as crianças vivenciam, maior se torna o leque de repertório motor. Quanto mais a criança socializa em espaços distintos, como a escola, comunidades, pessoas, Brinquedoteca, mais processos discursivos, comportamentos e ações elas presenciam. São experiências que passam a fazer parte das culturas infantis. Essas culturas, em que o brincar se 
torna uma ação sublime, torna-se, em nossa concepção, uma obra de arte que pretendemos preservar e estudá-la.

\section{O BRINCAR COMO OBRA DE ARTE NA INFÂNCIA}

Partimos do pressuposto que o brincar é uma dinâmica essencial da criança, embora não seja atividade exclusivamente infantil, como algo que surge do nada e naturalmente. Com base nos estudos e teoria de Brougère (2002; 2010), reforçamos tal ideia e destacamos que o brincar se caracteriza como uma atividade sublime na infância, compreendida, aqui, como obra de arte que carrega analogias e sentidos.

A esse respeito, Cunha e Gonçalves (2015) dizem que a infância - na manifestação de ser criança e de brincar - acaba por ser uma verdadeira obra de arte, como uma espécie de abertura, até mesmo de uma aceitação do novo, do imaginário, do inesperado. Citando Vasconcelos (2009), Cunha e Gonçalves (2015) dizem que ser "criança é poder apreciar, ainda que por um espaço de tempo muito breve, um tempo em que a tremenda dimensão do horror da ideia do crescimento - e, portanto, da morte - ainda não apresenta com nitidez e realismo.

O brincar (e a brincadeira) na infância, na direção desse pensamento, assume magnitude ímpar por ser comparada a uma obra de arte. Arte porque o protagonista, durante $\mathrm{o}$ ato de brincar, confere um tom artístico, pinceladas de arte, constrói maneiras diferentes ao fazer e inserir suas impressões, experiências e vivências naquela ação brincante.

Quando pensamos nas brincadeiras que acontecem na Brinquedoteca, vale destacar que muitas cenas que as crianças produzem e reproduzem carregam elementos da cultura midiática. É perceptível quando escolhem os brinquedos e, nos grupos de pares, incorporam personagens que se destacam na televisão, como super heróis. São questões que nos debruçamos para perceber de que modo esses fenômenos refletem em suas práticas corporais e na construção de significados que as crianças constroem. Trata-se de culturas lúdicas infantis.

A cultura lúdica é definida como um conjunto de regras e significações do jogo, o que resulta na ação em que o jogador adquire e domina o seu contexto. Em outras palavras, o jogo consiste no lugar de emergência e enriquecimento da cultura lúdica, como explica Brougère (2002). 
Como afirma Brougère (2002), a cultura lúdica como toda cultura é um produto da interação social. Vemos com ele que é a partir das relações estabelecidas entre criança, brinquedo e meio social que os sujeitos constroem suas culturas lúdicas. A cultura lúdica, diz Brougère, visto resultar de uma experiência lúdica, é produzida pelo sujeito social a partir dessas relações e interações que envolvem indivíduos, ações e objetos materiais.

Direcionando a discussão para compreendermos, brevemente, sobre o conceito de infância, enfatizamos que se trata de algo novo, a considerar o ponto de vista histórico. Segundo Oliveira (2005, p. 105), o conceito de infância na área acadêmica, especificamente na Educação Física, ainda carrega alguns vestígios do conceito constituído historicamente na sociedade. Esse movimento conceitual está ancorado nos pressupostos dos sentimentos de paparicação e moralização, muito bem trazidos à tona por Ariès ${ }^{3}$, que representam uma idealização da infância.

Sob outra vertente, contrariamente a essa perspectiva, é importante destacar as ideias do renomado pesquisador da Sociologia da Infância, Manuel Sarmento, em que temos aprofundado, que em 2005 criticou a visão pejorativa da infância pela sociedade, e seu consequente afastamento do mundo adulto, no artigo "Gerações e Alteridade”. Para Sarmento (2005), a geração da infância não é apenas uma fase de maturação biológica e desenvolvimento humano intermediário, e sim um objeto de investigação sociológica e uma categoria social de extrema relevância, a qual é continuamente modificada por ações internas e externas de elementos que compõem sua realidade, incluindo os meios de comunicação.

As travessuras e vicissitudes infantis, bem como os diferentes modos de ser criança, têm sido alvo de bastante investigação do professor Sarmento, membro do Centro de Investigação em Estudos da Criança da Universidade do Minho (Portugal). No Brasil, com base em investigações realizadas em Portugal, temos desenvolvido ações entre comunidade, profissionais da educação e Universidade para contribuir com a construção de novos sentidos, diferentes significados e construção de conhecimentos que possam refletir na sociedade. Por meio de

3 Ariès inaugurou um importante debate em sua obra que explora o surgimento do sentimento da infância, a relação da criança e família, apresentando a imagem construída socialmente da infância na iconografia, desde o período da idade medieval. Para maior aprofundamento dessas questões, consultar a obra completa: ARIÈS, P. História social da criança e da família. 2 ed. Rio de Janeiro: LTC, 2006. 
oficinas (lúdicas), episódios, intervenções e observações participantes, pretendemos apresentar possibilidades distintas para pensar e educar, que tem sido possível porque existem pilares advindos da extensão e da pesquisa.

\section{Oficinas E EPISÓdios QUE MOTIVAM A PENSAR E EDUCAR NA BRINQUEDOTECA}

O projeto de extensão que atende crianças de escolas públicas do município, desenvolvido há três anos, ao longo desse período promoveu encontros, rodas de conversas e grupos de discussão e formação a partir de questões que as próprias crianças trazem à tona no espaço lúdico. Temas como gênero, brincadeiras violentas, sexualidade e heróis midiáticos, são os mais emergentes.

Por meio de assuntos emblemáticos e suscitados no contexto educativo, enquanto as crianças brincam livremente, propomos oficinas que permitem colher informações para, conseguinte, discutir, explorar, analisar e compartilhar. Foi nesse sentido que aconteceu a primeira oficina, denominada "Brinquedos de menino, de menina ou dos dois?" Tal oficina objetivou analisar como as crianças e suas professoras classificam alguns brinquedos da Brinquedoteca, com objeto designado para menino, menina ou os dois. Foram selecionados 34 brinquedos que as crianças já haviam estabelecido algum tipo de contato no interior da Brinquedoteca, para não distanciar da realidade dos mesmos.

A oficina foi realizada com as crianças e suas respectivas professoras da Educação Infantil. Os participantes foram convidados a ajudar a separar os brinquedos que estavam dispostos dentro de uma única caixa. Assim, ao ser retirado cada objeto o público deveria dizer se aquilo era uma "coisa" só de menino, só de menina ou dos dois, para então ser separado. Havia brinquedos como bonecas, bolas, jogos coloridos, celular, ursinhos, entre outros.

A oficina foi desenvolvida em duas etapas distintas: primeiro com as crianças e depois com as professoras da turma. A primeira parte da oficina aconteceu com as crianças sem a presença das professoras. Ao retirar cada objeto da caixa e consultar a opinião do grupo de crianças, os brinquedos foram colocados, um a um, dentro de um bambolê que estava posicionado ao chão, na frente das crianças. Havia três bambolês no chão, um destinado para cada tipo de resposta: o de menino, o de menina e o que representava os dois. 
Quando terminou a oficina, verificamos que quinze brinquedos foram selecionados pelas crianças como algo exclusivo de meninos, outros quinze brinquedos foram classificados por elas como sendo exclusivamente de meninas, e apenas quatro foram direcionados para o bambolê como algo que tanto os meninos quanto as meninas poderiam brincar.

Importa destacar que a mesma oficina foi realizada com as professoras das crianças, justamente pelo fato das mesmas apresentarem comportamentos que direcionassem as brincadeiras das crianças de acordo com os tipos de jogos e brinquedos. A oficina permitiu identificar algumas diferenças nas respostas. Treze brinquedos foram indicados como sendo exclusivos de meninas e dez dos objetos, são, para elas, para meninos. Por outro lado, onze brinquedos foram eleitos como algo que pode ser tanto de meninos, quanto de meninas.

A esse respeito, as considerações e análises de Kishimoto e Ono (2008) merecem ser trazidas para o texto pelo fato de contemplar aspectos que caminham nesse sentido. Ao problematizar brinquedo, gênero e educação na Brinquedoteca, as pesquisadoras defedem a importância de meninos e meninas brincarem juntos e, ressalta, ainda, que é preciso eliminar os preconceitos de gênero, que dependem de fatores externos à Brinquedoteca, atrelados à formação, que ainda existem nos ambientes educativos, como a escola e a Brinquedoteca.

Outra oficina também permitiu a discussão de outros assuntos relativos à criança, mídia e personagens (heróis) da televisão (TV). Denominada "oficina da TV: quando as crianças entram em cena na televisão", esta teve como objetivo analisar os modos de ser e brincar das crianças quando elas imaginam que estão "dentro" da televisão.

Para a realização desta ação, primeiramente os estudantes da graduação participaram da construção de uma televisão fictícia, utilizando uma caixa de papelão de fogão. Após esta etapa, convidamos as crianças a conhecer o objeto construído, explicando que aquela obra consistia em uma grande televisão de brincadeira, e na sequência deixamos a caixa no centro da Brinquedoteca. A TV de papelão recebeu tinta em spray na cor preto e a equipamos com uma antena em formato de "v", fixada na parte superior. A parte frontal possuía a frente recortada, com uma janela que permitia a criança adentrar o espaço. Essa mesma janela se caracteriza como a tela da televisão.

Durante a oficina com a televisão, em que participaram crianças entre 3 e 5 anos, tivemos como foco de análise observar as ações das crianças ao 
adentrarem o espaço. Do que elas brincavam e o que elas diziam muito nos interessou. Os fenômenos e episódios que acontecem na Brinquedoteca são registrados em um diário de campo, elaborado e alimentado pelo pesquisador, estudantes bolsistas e voluntários do projeto de extensão/pesquisa. Percebemos que algumas crianças entravam na caixa acompanhadas com outros colegas, enquanto outras brincavam sozinhas. As crianças conversavam e, em algumas situações e nos explicavam alguns fenômenos.

No contexto da oficina registramos muitas cenas, episódios, acontecimentos e situações. Ao deixar a televisão no centro da Brinquedoteca, registramos três situações ocorridas, que merecem ser descritas:

\footnotetext{
As crianças entraram na TV e disseram que eram outras pessoas (personagens) e simulam brincar de desenho animado, como a Pepa Pig, o Homem Aranha, a Masha e o Urso e o desenho da Pantera. Durante outra situação, observamos duas crianças que, ao entrarem na TV, disseram que iriam fazer um jornal de polícia e ladrão. Ao indagar sobre como conheciam esse jornal de polícia e ladrão, eles disseram que assistem na televisão com seus pais à noite. Em outro momento, uma menina estava dentro da TV e havia outra do lado de fora. Ambas estabeleciam uma comunicação. A que estava do lado de dentro disse que estava pagando contas, utilizando um tablet. Em seguida pegou o Ursinho panda e começou a dar de mamar, dizendo que era seu filho4.
}

Durante os momentos em que as crianças brincam elementos da cultura midiática se fazem presentes, como os super heróis, que povoam suas fantasias e imaginações, modificando o enredo das culturas lúdicas infantis. $\mathrm{O}$ acesso a televisão, bem como aos seus programas, permite a construção de imagens, sentidos e significados advindos de cenas da vida cotidiana que são expostas às pessoas que com eles interagem. A reprodução interpretativa, conceito importante na Sociologia da Infância, cunhado por Corsaro (2011), explica essas reproduções de comportamentos do universo adulto que também aparecem nas brincadeiras infantis.

Os professores das crianças são convidados a discutirem os assuntos que as elas trazem à tona, como os expostos acima. Por meio da realização de leituras - artigos, livros e outros conteúdos - que tratam dos temas em questão, estudantes da graduação e orientador propõem rodas de conversa e problematizam

4 Registro do diário de campo dos pesquisadores - outubro/2017. 
assuntos convidando o adulto a refletir sobre os discursos e significados que as crianças atribuem às coisas, objetos e ações que vivenciam.

Sob outra perspectiva, algumas brincadeiras também foram utilizadas como base para trabalhar conceitos importantes (jogo, brincadeira, cultura lúdica) com a comunidade acadêmica envolvida no projeto, de modo a refletir nos profissionais da escola. Quando professores da Educação Infantil aprendem mais sobre o universo da criança, desprendendo de concepções enraizadas, preconceituosas e tradicionais, é possível educar para desenvolver a autonomia, a liberdade de brincar e, consequentemente, desperta o senso crítico.

Pelo fato de ser muito constante as brincadeiras com "assaltos, tiros, lutinhas e porradas", na Brinquedoteca, trazemos episódios capazes de explorar algumas questões, como a "violência no jogo e brincadeiras agressivas", como são denominadas por alguns educadores.

$\mathrm{Na}$ Brinquedoteca Universitária acontecem várias situações, compreendidas por nós como reproduções de realidades vivenciadas pelas crianças no dia a dia ou até mesmo algo extraído da veiculação de informações e conteúdos que circulam na mídia e outros meios de comunicação. $\mathrm{O}$ adulto, bem como a criança, estabelece contato com diferentes tipos de informações e conteúdos midiáticos que se fazem presentes nos lares, na rua, no comércio, etc.

É pertinente abordar que por meio das observações na Brinquedoteca, percebemos que, por um lado, as professoras das crianças "toleram" e permitem que elas brinquem com lutas, reproduzindo golpes, gestos, simulações de poder, incorporando personagens, como os Power Rangers ou outros heróis, por exemplo. Por outro lado, quando as crianças utilizam armas (revólver) para brincar de polícia e ladrão ou assaltos, as professoras das crianças inibiam a ação lúdica com tais objetos.

Nossa ênfase não é oferecer um projeto de extensão para a criança aprender "violência" na Brinquedoteca enquanto brinca. Não se trata, aqui, de promover e valorizar um aspecto profano da "arminha" de brinquedo (revólver de plástico) enquanto instrumento que pode ser ou não algo tendencioso ou perverso. A questão é colocar em suspenso, como grupo de estudos da academia, as (re)produções de uma cultura lúdica, como a exposta anteriormente, em que as crianças, muitas vezes, utilizam tais objetos para brincar, compreendendo que esses não se caracterizam como elementos que influenciam suas personalidades e vidas de maneira negativa. 
Brougère (2010) aborda muito bem essa questão quando relata as brincadeiras e brinquedos de guerra em sua obra "Brinquedo e Cultura". O teórico francês relata principalmente a dimensão cultural da brincadeira e do brinquedo, deixando para outros estudiosos o cuidado de destacar a dimensão psicológica que, muitas vezes, leva para outros aspectos e representações de violência e agressividade. Conforme argumenta, a criança, quando quer brincar com uma arma, nem precisa de uma réplica de plástico, ela pode utilizar as próprias mãos para fazer uma simulação. Não é porque a criança brinca com arma ou aponta o dedo que ela se tornará um bandido.

Esse fenômeno deixa evidente, como afirma Brougère (2010), que a criança pode apontar qualquer objeto, ou usar a própria mão com os dedos, que sua imaginação poderia construir muitas situações e maneiras diferentes de brincar. Do mesmo modo, a criança pode brincar com uma arma de brinquedo e imaginar que a aquele objeto pode ser um celular, um avião, qualquer outro brinquedo.

A imaginação, nesse aspecto, além de ser um aspecto importante ser explorado na da escola, ou na Brinquedoteca, torna-se uma maneira leal e bastante significativa de estabelecer contato com a criança, de modo a proporcionar situações de liberdade e de criação dentro de um contexto que é a Educação Infantil. Silva (2015) reforça que o papel do professor consiste em identificar e compreender esses elementos, construir estratégias para explorar junto às crianças e, partir daí, tornar suas aulas um grande e encantador "laboratório de descobertas", em que a porta de entrada seja a curiosidade.

Assim, temos trabalhado de maneira a provocar reflexões entre estudantes e professores da rede pública de ensino, convidando-lhes a estabelecer relações dialógicas com as crianças, de modo a possibilitar a construção de significados, junto às crianças, sobre assuntos emergentes no cotidiano, sobretudo àqueles que elas trazem à tona em suas brincadeiras e rodas de conversas. Com isso, apropriamo-nos das brincadeiras infantis para nos aproximarmos mais das crianças e consequentemente dialogar, educar e intervir. Os temas a serem trabalhados nesses processos educativos são inúmeros e não se esgotam, como as brincadeiras de lutas, tiros, polícia e ladrão, entre outras. 


\section{Potencialidades de uma Bringuedoteca Universitária: Algu-} MAS CONSIDERAÇÕES

A Brinquedoteca Universitária é um dos vários espaços propícios à produção de culturas lúdicas infantis, entre outros infinitos locais. Dentre as várias possibilidades de um laboratório de ludicidade, como assim a denominamos e a compreendemos, está o caráter formativo. A dimensão do aspecto educativo-formativo extrapola as paredes da escola e chega à Brinquedoteca Universitária.

Paula Sibilia (2012) propõe uma discussão que nos provoca a pensar na escola em tempos de dispersão, oferecendo subsídios que colocam em suspenso uma configuração de escola sustentada por redes ou paredes. Ao questionar para que serve a escola, Sibilia (2012) apresenta uma série de inquietações que balançam certezas. Explora o aspecto do quadro negro e sua substituição silenciosa pelas telas, fazendo analogias que confrontam a "conexão" e o "confinamento".

Ao convidar crianças e professores da rede municipal para participarem do projeto de extensão, que consiste simplesmente em participar dos encontros na Brinquedoteca da faculdade, trabalhamos no sentido de romper com as paredes da escola, ao retirar do seu interior sujeitos que possam aprender, também, fora do ambiente escolar.

Nesse sentido, ressaltamos a existência de potencialidades de trabalho educativo, destacando suas muitas vertentes e possibilidades, sobretudo por tomarmos como base a dimensão infância, cultura lúdica e Brinquedoteca. Vários são os estudos, entre eles o de Vectore e Kishimoto (2001) e Galindo et al (2012), que apresentam alternativas distintas para educar nesses contextos, sobretudo a partir de interações entre crianças e adultos/educadores.

Vectore e Kishimoto (2001) destacam vários elementos importantes a serem considerados, como o lugar na criança na Brinquedoteca, o papel do brinquedista, este que desempenha um papel que escapa de condutas autoritárias, a importância do brincar e o lugar do adulto que o acompanha.

Sabendo que existem modelos e formas diferentes de construir uma Brinquedoteca, Hypolitto (2001) apud Galindo et al (2012), afirma que cada Brinquedoteca apresenta o perfil da comunidade o qual lhe deu origem. Como o Laboratório implantado na faculdade mencionada objetiva trabalhar com crianças que não possuem espaços lúdicos em suas escolas, a Brinquedoteca Universitária torna-se uma extensão da escola, ao propiciar a visita de várias crianças da Educação Infantil, junto com seus professores e monitores. 
O que pode, então, uma Brinquedoteca Universitária? Galindo et al (2012, p. 181) dizem que as "Brinquedotecas, ao se constituírem como espaços abertos à produção da cultura lúdica, apresentam-se como um terreno fértil para os diálogos e as práticas intergeracionais". Portanto, o contato entre gerações diferentes, crianças, jovens e velhos, potencializam trocas intergeracionais, que ocorrem em contextos educativos, como a Brinquedoteca.

Tizuko Kishimoto, em 1998, no seu capítulo “Diferentes tipos de Brinquedoteca", registrou a existência de pelo menos nove tipos diferentes de Brinquedotecas. Segundo a autora, esses espaços podem ser: montados em creches e escolas; em comunidades ou bairros; para crianças que possuem deficiências físicas ou mentais; em hospitais; Brinquedotecas itinerantes, circulantes, em ônibus; em clínicas psicológicas; em centros culturais; aquelas temporárias, em shoppings, lojas; e a Brinquedoteca Universitária, esta que visa formar recursos humanos, trabalhar com a extensão e pesquisa.

Com todas essas variedades, podemos definir a Brinquedoteca como um espaço lúdico por meio de um ambiente que convida as crianças a explorar, experimentar, sentir, produzir culturas lúdicas de acordo com tempos e espaços próprios da infância. Nesse sentido, a escolha dos brinquedos e das brincadeiras que as crianças constroem deve ser livre. A criança não pode deixar de brincar com um brinquedo só porque ele possui cor rosa. A menina pode brincar com carrinho, sim. O menino pode brincar com a boneca também. As discussões provocadas no âmbito desse grupo, com base em textos científicos que abordam os temas aqui apresentados, têm proporcionado diferentes formas de olhar para a brincadeira infantil, e, por conseguinte, novos modos de educar e intervir na escola e na Brinquedoteca.

Assim, a Brinquedoteca Universitária, ao ser caracterizada como Laboratório de Ludicidade que tem como elemento central o desenvolvimento de pesquisas a partir de metodologias que se apropriam de intervenções, oficinas e observações participantes, tanto com as crianças quanto com os professores, oferece à comunidade um ambiente com brinquedos e recursos diversos que, além de contribuir com o exercício do direito de brincar, na infância, nos permitem pensar, refletir, aprender, para, também, respeitar e educar.

\section{REFERÊNCIAS}

ARIĖS, P. História social da criança e da família. 2 ed. Rio de Janeiro: LTC, 2006. 
BROUGÈRE, G. A criança e a cultura lúdica. In: KISHIMOTO, T. M. O brincar e suas teorias. São Paulo: Pioneira Thomson Learning, 2002.

BROUGÈRE, G. Brinquedo e cultura. 8. ed. São Paulo: Cortez, 2010. (Coleções questões da nossa época; v. 20).

CORSARO, W. A. Sociologia da infância. Porto Alegre: Artmed, 2011.

CUNHA, A. C.; GONÇALVES, S. T. A criança e o brincar como obra de arte: analogias e sentidos. $1^{\text {a }}$ Ed. Portugal: Whiteboooks, 2015.

GALINDO, D.; SALGADO, R. G.; LEMOS-DE-SOUZA, L. MOURA, M. M. Trocas geracionais: o que pode uma brinquedoteca universitária? In: ANDRADE, D. B. S. F.; LOPES, J. J. M. (orgs.). Infâncias e crianças: lugares em diálogos. Cuiabá: EdUFMT, 2012.

KISHIMOTO, T. Diferentes tipos de brinquedoteca. In: FRIEDMANN, A. O direito de brincar: a brinquedoteca. 4 ed. São Paulo: Abrinq, 1998.

KISHIMOTO, T.; ONO, A. T. Brinquedo, gênero e educação na brinquedoteca. Pro-Posições, v. 19, n. 3 (57) - set./dez. 2008.

OLIVEIRA, N. R. C. de O. Concepção de infância na educação física brasileira: primeiras aproximações. Revista Brasileira de Ciências do Esporte, Campinas, v. 26, n. 3, p. 95 109, maio. 2005.

POLETTO, R. C. A ludicidade da criança e sua relação com o contexto familiar. Psicologia em Estudo, Maringá, v. 10, n. 1, p. 67-75, jan./abr. 2005.

PRESTES, Z.; TUNES, E. A brincadeira infantil na perspectiva histórico-cultural. In: ANDRADE, D. B. S. F.; LOPES, J. J. M. (orgs.). Infâncias e crianças: lugares em diálogos. Cuiabá: EdUFMT, 2012.

PROUT, A. Reconsiderando a nova sociologia da infância. Cadernos de Pesquisa, v.40, n.141, p.729-750, set./dez. 2010.

QVORTRUP, J. A infância enquanto categoria estrutural. Educação e Pesquisa, São Paulo, v. 36, n. 2, p. 631-643, maio/ago. 2010.

SARMENTO, J. Gerações e alteridade interrogação a partir da sociologia da infância. Revista Educação e Sociedade, Campinas, v. 26, n. 91, p. 361-368, maio/ago. 2005.

SILVA, D. O. Desenvolvendo um cenário imaginativo circense pelo brincar-e-se-movimentar da criança. Dissertação de mestrado - Programa de Pós-Graduação em Educação Física, Universidade Federal de Santa Maria, Rio Grande do Sul, Brasil, 2015.

VECTORE, C.; KISHIMOTO, T. M. Por trás do imaginário infantil: explorando a brinquedoteca. Psicologia Escolar e Educacional, Volume 5, Número 2, p. 59-65. 2001. 